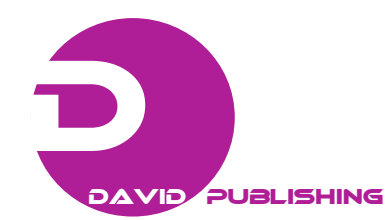

\title{
Antioxidant Capacity and Total Phenol Content of Commonly Consumed Indigenous Foods of Asian Tropical Regions
}

\author{
Nazma Shaheen ${ }^{1}$, Masao Goto ${ }^{2}$, Jun Watanabe ${ }^{2}$ and Yuko Takano-Ishikawa ${ }^{2}$ \\ 1. Institute of Nutrition and Food Science (INFS), University of Dhaka, Dhaka 1000, Bangladesh \\ 2. Functional Food Factor Laboratory, Functional Food Division, National Food Research Institute (NFRI), Tsukuba, Ibaraki \\ 305-8642, Japan
}

Received: October 26, 2011 / Published: April 20, 2012.

\begin{abstract}
In order to screen the antioxidant capacity of commonly consumed indigenous foods of tropical region, vegetables, fruits, tea, oil seeds, legumes, spices and cereal were analyzed. Among the vegetables, green chili showed the highest total oxygen radical absorbance capacity $\left(\mathrm{ORAC}_{\mathrm{FL}}\right)$ and lipophilic ORAC (L-ORAC $\left.\mathrm{FL}_{\mathrm{FL}}\right)$; whereas, bean showed highest hydrophilic ORAC $\left(\mathrm{H}-\mathrm{ORAC} \mathrm{FL}_{\mathrm{FL}}\right)$ content. The H-ORAC $\mathrm{FL}_{\mathrm{FL}}$ of vegetable samples varied between 2.26 to $23.08 \mu \mathrm{mol}$ of Trolox equivalent (TE)/g of fresh weight (FW) and L-ORAC $\mathrm{FL}_{\mathrm{FL}}$ content widely varied from 0.20 (sweet pumpkin) to 16.95 (green chili). The range of $\mathrm{H}-\mathrm{ORAC} \mathrm{FL}_{\mathrm{FL}}$ values of fruits showed large variation $(0.45-178 \mu \mathrm{mol}$ of TE/g FW). All four different types of tea showed high H-ORAC $\mathrm{FL}(1,295.84-2,709.11$ $\mu \mathrm{mol}$ of $\mathrm{TE} / \mathrm{g}$ ), in contrast to negligible amount of L-ORAC $\mathrm{FL}_{\mathrm{FL}}$. In legumes, $\mathrm{H}-\mathrm{ORAC} \mathrm{FL}_{\mathrm{FL}}$ content ranged from 16.22 to 140.54; whereas,

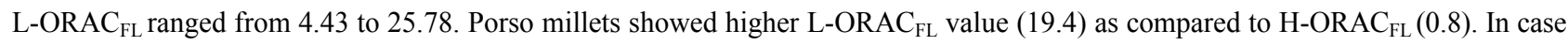
of spices, L-ORAC $\mathrm{FL}_{\mathrm{FL}}$ content varied from $29.75 \pm 0.00$ to $1,575.24 \pm 39.63$, which is considerably higher as compared to $\mathrm{H}-\mathrm{ORAC} \mathrm{CL}_{\mathrm{FL}}$ $(61.68 \pm 1.71$ to $272.82 \pm 1.05)$ content. Comparatively, spices showed much higher $\mathrm{H}-\mathrm{ORAC} \mathrm{FL}_{\mathrm{FL}}$ values as compared to fruits analyzed. In case of selective vegetables, fruits and tea samples, the total phenol content was highly correlated with the H-ORAC $\mathrm{FL}$ content.
\end{abstract}

Key words: Hydrophilic and lipophilic antioxidant capacity, polyphenol, indigenous foods, Bangladesh.

\section{Introduction}

Recent research findings and knowledge in food biochemistry and molecular biology strongly support the hypothesis that food can modulate various functions in the body in addition to supplying the basic nutrients. Considerable interest has been given on dietary antioxidants with reference to their protective role against oxidative damage $[1,2]$. Moreover, significant number of research findings suggested that oxidation and free radical mediated reactions are implicated in degenerative processes related to aging and diseases in old ages [3] and

Corresponding author: Yuko Takano-Ishikawa, Ph.D., researcher, research field: functional food factor. E-mail: yuko@affrc.go.jp. various degenerative diseases such as cancer, atherosclerosis and diabetes [4]. Reactive oxygen species (ROS) are constantly generated in vivo either through aerobic respiration of cells or induced by exogenous sources such as pollution, ionizing radiation and drugs or toxic compounds [5]. Living organisms protect themselves from oxidative damage by endogenous antioxidant defense systems [3] or by dietary antioxidant widely distributed in natural foods $[6,7]$. Natural antioxidants can be phenolic compounds (tocopherol, flavonoids and phenolic acids), nitrogen compounds (alkaloids, chlorophyll derivatives, amino acids and amines) or carotenoids, as well as ascorbic acid $[8,9]$.

The most recent terminology "Functional Foods" 
introduces a new dimension to the food science, that is, medicine and food have common origin [10]. The bioactive compounds, such as secondary metabolites of plant origin foods and also some nutrients are reported for their potential health beneficial role, which includes anti-carcinogenic [11], protective role against heart disease [12], anti-inflammatory, anti allergic roles [13]. Recently, reported that some common foods in daily life have been found to have anti-allergic effects and also identified a responsible bioactive compound [13].

Dietary polyphenols could be prominent source of antioxidants for human, derived from plants and are consumed in the forms of fruits, vegetables, spices and herbs [14]. Insignificant numbers of information are available on the content of phenolic compounds in common Bangladeshi food stuffs and their antioxidant activity [15]. This work is aimed to evaluate a selected number of vegetables, fruits, spices, pulses and herbs consumed in the local diet with respect to their total phenolic content and antioxidant capacity.

\section{Materials and Methods}

\subsection{Chemicals and Apparatus}

\section{2,2'-Azobis (2-methylpropionamide)} dihydrochloride (AAPH), all other solvents used for extraction and chemicals used for assay buffer were procured from Wako Chemicals, Japan. Torolox (6-Hydroxy-2, 5, 7, 8-tetramethylchroman2-carboxylic acid) was purchased from Aldrich, Denmark and Fluorescein isothiocyanate (FITC) from SIGMA, USA. Randomly methylated $\beta$-cyclodextrin (RMCD) was obtained from JUNSEI, Japan. Folin-Ciocalteau reagent was purchased from MP Biomedicals, LLC, Ohio/France and Gallic acid from TIC, Japan. Extractions of samples were performed on an ASE 200 accelerated solvent extractor (DIONEX, Japan).

\subsection{Samples Collection}

Most of the samples of 14 vegetables were collected as fresh as possible from home garden (Tomato, Radish, Carrot, Cucumber, Eggplant, Sweet Pumpkin, Cabbage, Bottle gourd, Green Chili, Bean, Okra, Onion, and Spinach), 6 fruits (Papaya, Banana, Guava, Indian Apple, Water Melon, and Amla) were collected from local market of Dhaka, a capital of Bangladesh, four Tea samples were collected from Tea garden of Sylhet, North-eastern hilly area of Bangladesh and rest of the samples e.g., oil seeds which includes Linseed, Mustard (Red), Mustard (Yellow), Sesame (Black), Sesame (Brown), legumes includes Black gram, Green gram, Khesari, Lentil, and Bengal gram, Spices includes Red Chilli, Turmeric, Coriender, Radhuni and Mouri and porso mellet (Chinna) were collected from the cultivars level.

\subsection{Samples Preparation}

The collected food samples were processed in the Food analysis Laboratory of Institute of Nutrition and Food sciences (INFS), University of Dhaka, Bangladesh. Fresh vegetables and fruits were freeze-dried after washing with deionized water, making small pieces of edible portion after removal of extra water and kept at $-20{ }^{\circ} \mathrm{C}$ before analysis. Tea, Oil seeds, Legumes, Cereal and Spices were kept at $-20{ }^{\circ} \mathrm{C}$ in their original dried form until analysis. All samples were grinded well by millcer-800DG, IWATANI, Japan, before extraction, was packed in low-density polyethylene pouches and preserved at $8-10{ }^{\circ} \mathrm{C}$ for further analysis. Ground food samples $(0.5-1.0 \mathrm{~g})$ was mixed with food matrix (Varian, sample preparation products, A) to made final weight $2.5 \mathrm{~g}$, then transferred to a $22 \mathrm{~mL}$ extraction cell and initially extracted with hexane/dichloromethane $(1: 1$, Hex/Dc) followed by acetone/water/acetic acid (70:29.5:0.5; AWA). Both the hexane/ dichloromethane and AWA extracts were transferred to $25 \mathrm{~mL}$ measuring cylinder and adjust the volume with extraction solvent to $25 \mathrm{~mL}$ of total volume. AWA extracts was used for the determination of hydrophilic $\mathrm{ORAC}_{\mathrm{FL}}$ and TPC after proper dilution. After adjustment of Hexane/Dicholoromethane 
extracts to final volume of $25 \mathrm{~mL}$, an aliquot of the extracts was transferred to screw capped glass tube to store at $4{ }^{\circ} \mathrm{C}$. Before estimation of L-ORAC $\mathrm{FL}_{\mathrm{FL}}$ an aliquot of Hex/Dc extracts were dried under nitrogen flow in a $37{ }^{\circ} \mathrm{C}$ heating block, then dissolved by acetone (half of the volume of the aliquot of extracts was taken) and after mixing well, equal volume of $7 \%$ Randomly methylated $\beta$-cyclodextrin (RMCD) in a $50 \%$ acetone-water mixture $(\mathrm{v} / \mathrm{v})$ was added and shaken for $1 \mathrm{~h}$ at room temperature on an orbital shaker at $400 \mathrm{rpm}$, if not dissolved by acetone $[16,17]$ and used for analysis of lipophillic $\mathrm{ORAC}_{\mathrm{FL}}$ after further dilution with 7\% RMCD solvent if needed.

\subsection{Anti-oxidant Capacity of the Sample Extracts by} ORAC $_{F L}$ Assay

The ORAC value was evaluated according to the method of Huang et al. [18]. Stock solution of fluorescein sodium salt (Sigma, St. Louis, MO) (7.17 $\mu \mathrm{M})$ was prepared in phosphate buffer $(\mathrm{pH} 7.0)$. The working solution $(71.7 \mathrm{nM})$ was obtained by subsequent dilution of stock solution with PBS. 2,2'-Azobis (2-amidinopropane) dihydrochloride (AAPH), (Wako Pure Chemicals Industries, Japan) was prepared freshly at a concentration of $200 \mathrm{mM}$ and used after $10 \mathrm{~min}$. heating at $37^{\circ} \mathrm{C}$ and zero time fluorescein intensity. Calibration curve $(50,25,12.5$, $6.25 \mu \mathrm{M})$ of Torolox (6-hydroxy-2, 5, 7, 8-tetramethylchroman-2-carboxylic acid) (Sigma, St. Louis, MO) were prepared during every estimation by diluting the stock solution ( $2 \mathrm{mM}$ ) with PBS. Diluted samples $(25 \mu \mathrm{L})$ solution was mixed with fluorescein $(150 \mu \mathrm{L})$ and incubated at $37{ }^{\circ} \mathrm{C}$ for $10 \mathrm{~min}$ in the microplate reader. The analyzer was programmed to record the flouresence of FL every minute after addition of AAPH $(25 \mu \mathrm{L})$ solution and the microplate was shaken. The fluorescence was measured at 490 $\mathrm{nm}$ for excitation and $535 \mathrm{~nm}$ for emission in a multilabel counter (Wallac, $\mathrm{ARVO}_{\mathrm{TM}} \mathrm{SX}$, Perkin Elmer, and Life Science) and previously before addition of AAPH zero $h$ fluorescence was measured. All measurements were expressed relative to the initial reading. Final results were calculated using the differences of areas under the FL decay curves between the blank and a sample. These results were expressed as $\mu$ moles Torolox equivalent (TE).

\subsection{Total Phenol Analysis}

The total phenol contents of the samples were measured by the modified Folin-Ciocalteu method [19]. Gallic acid calibration solutions (100, 50, 30, 20 and $10 \mathrm{mg} / \mathrm{g}$ ) were made and run on the multidetection microplate reader (Powerscan $^{\mathrm{TR}}$, Dainippon Sumitomo Pharma, Japan) to obtained standard curve for gallic acid and estimation of TP content of the AWA extracts of samples. The results were expressed as $\mathrm{mg}$ of gallic acid equivalents per gram of sample (mg of GAE/g).

\section{Results and Discussion}

Numerous in vitro methods have been developed for the assay of antioxidant capacity of foods and according to many reports and review article, most popular in vitro antioxidant measurements already recommended ORAC assay as an excellent method to obtained accurate results by using a multichannel liquid handling system coupled with a fluorescence micro plate reader in 96 well formats [18]. ORAC represent a hydrogen atom transfer (HAT) reaction mechanism, which is most relevant to human biology. The Folin-Ciocalteu method is an electron transfer (ET) based assay and gives reducing capacity, which has normally been expressed as phenolic contents. Accordingly, Oxygen Radical Absorbance Capacities (ORAC) assay has been employed for the determination of antioxidant capacity for the initial screening in present study [20]. Total phenol of each sample was measured by using the modified Folin-Ciocalteu reagent [19].

\subsection{ORAC $F L$ of Vegetables and Fruits}

The antioxidant activity of hydrophilic and lipophilic fraction of vegetables and fruits expressed as $\mathrm{H}_{-} \mathrm{ORAC} \mathrm{FL}_{\mathrm{FL}}, \mathrm{L}-\mathrm{ORAC} \mathrm{FL}_{\mathrm{FL}}$, which is given in Table 1 with 


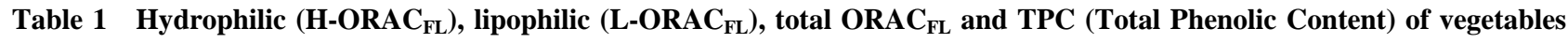
and fruits*.

\begin{tabular}{|c|c|c|c|c|c|c|}
\hline $\begin{array}{l}\text { Vegetables/ } \\
\text { Fruits }\end{array}$ & Scientific name & $\begin{array}{l}\text { Moisture } \\
(\%)\end{array}$ & $\begin{array}{l}\text { H-ORAC } \mathrm{FL} \\
\left(\mu \mathrm{mol} \mathrm{TEg}{ }^{-1}\right)\end{array}$ & 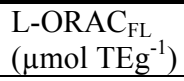 & 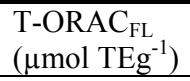 & $\begin{array}{l}\mathrm{TP}(\mathrm{mg} \\
\left.\mathrm{GAEg}^{-1}\right)\end{array}$ \\
\hline TOM (Tomato) & Lycopersicon esculentum & 92.98 & $4.50 \pm 0.72$ & $1.10 \pm 0.40$ & 5.60 & 1.5 \\
\hline RAD (Radish) & Raphanus sativus & 96.93 & $2.72 \pm 0.21$ & $0.25 \pm 0.11$ & 2.97 & 0.60 \\
\hline CAR (Carrot) & Daucus carota & 90.63 & $2.83 \pm 0.25$ & $0.93 \pm 0.35$ & 3.76 & 1.09 \\
\hline CUC (Cucumber) & Cucumis sativas & 94.47 & $2.41 \pm 0.30$ & $0.51 \pm 0.10$ & 2.92 & 0.80 \\
\hline EGG (Eggplant) & Solanum melongena wall. & 71.64 & $15.48 \pm 4.65$ & $7.89 \pm 2.30$ & 23.37 & 13.91 \\
\hline PUM (Sweet pumpkin) & Cucurbita maxima.Duch. & 94.54 & $2.26 \pm 0.43$ & $0.20 \pm 0.03$ & 2.46 & 0.83 \\
\hline CAB (Cabbage) & Brassica Oleracea(L) Penn. & 93.54 & $4.47 \pm 0.63$ & $0.31 \pm 0.04$ & 4.78 & 1.42 \\
\hline BOG (Bottle gourd) & Lagenaria vulgaris & 95.29 & $2.32 \pm 0.05$ & $0.77 \pm 0.06$ & 3.09 & 0.50 \\
\hline GRC (Green chili) & Capsicum annum & 85.92 & $19.89 \pm 2.23$ & $12.36 \pm 1.56$ & 32.25 & 3.60 \\
\hline BEA (Bean) & Phaseolus coccineus & 80.05 & $23.08 \pm 3.76$ & $4.76 \pm 0.30$ & 27.84 & 3.10 \\
\hline BIG (Bitter gourd) & Momordica charantia & 93.63 & $2.74 \pm 0.30$ & $1.47 \pm 0.08$ & 4.11 & 0.91 \\
\hline OKR (Okra) & Abelmosschus esculentus & 87.77 & $16.95 \pm 0.64$ & $1.36 \pm 0.04$ & 18.31 & 5.75 \\
\hline ONI (Onion) & Allium сера & 83.13 & $11.17 \pm 1.26$ & $0.77 \pm 0.08$ & 11.94 & 2.41 \\
\hline SPI (Spinach) & Spinacia oleracea & 90.8 & $14.15 \pm 1.78$ & $2.13 \pm 0.20$ & 16.28 & 3.93 \\
\hline PAP (Papaya) & Carica papaya & 91.05 & $2.72 \pm 0.60$ & $0.26 \pm 0.03$ & 2.98 & 1.38 \\
\hline BAN (Banana) & Musa paradisiaca & 72.53 & $5.72 \pm 0.70$ & $2.50 \pm 0.29$ & 6.22 & 6.13 \\
\hline GUA (Guava) & Psidium guajava & 82.87 & $43.52 \pm 5.40$ & $4.27 \pm 0.93$ & 47.79 & 13.75 \\
\hline WOA (Wood apple) & Aegle marmelos & 74.07 & $177.81 \pm 18.21$ & $1.52 \pm 0.38$ & 179.33 & 18.97 \\
\hline WAM(Water melon) & Citrullus vulgaris & 97.77 & $0.45 \pm 0.02$ & $0.06 \pm 0.03$ & 0.51 & 0.21 \\
\hline AML (Amla) & Embilica officinalis & 90.44 & $87.15 \pm 3.23$ & $0.21 \pm 0.03$ & 87.36 & 157.86 \\
\hline
\end{tabular}

*Values expressed as fresh weight basis and presented as mean \pm SD for three different estimations.

TPC (Total Phenolic Content). The range of $\mathrm{H}-\mathrm{ORAC} \mathrm{CL}_{\mathrm{FL}}$ values of the vegetables varies 2.32 to $23.08 \mu \mathrm{mol}$ $\mathrm{TEg}^{-1} \mathrm{FW}$ and of all vegetables analyzed Phaseolus coccineus (bean), Capsicum annum (green chili), Abelmosschus esculentus (okra), Solanum melongena wall. (egg plant), Spinacia oleracea (spinach) contained higher value as compared to other vegetables analyzed in the present study. Among the fourteen vegetables analyzed, Capsicum annum has highest T-ORAC $\mathrm{FL}_{\mathrm{FL}}$, whereas, Phaseolus coccineus has higher $\mathrm{H}-\mathrm{ORAC} \mathrm{C}_{\mathrm{FL}}$ as compared to Capsicum annum. In case of L-ORAC $\mathrm{FL}_{\mathrm{FL}}$, Capsicum annum and Solanum melongena contained higher value as compared other vegetables assayed, indicating the presence of lipid soluble bioactive compounds. However, recent review of food composition database for bioactive food components reported that Solanum melongena contained beta-sitosterol and stigmasterol [21]. According to the order of higher to lower ORAC values of the vegetables are as follows:
Capsicum annum $>$ Phaseolus coccineus $>$ Solanum melongena wall. > Abelmosschus esculentus > Spinacia oleracea $>$ Allium cepa $>$ Lycopersicon esculentum > Brassica Oleracea (L) Penn. > Momordica charantia $>$ Daucus carota $>$ Lagenaria vulgaris > Raphanus sativus > Cucumis sativas $>$ Cucurbita maxima. Duch

The correlation between $\mathrm{H}-\mathrm{ORAC} \mathrm{FL}_{\mathrm{FL}}$ and $\mathrm{TPC}$ shows that only Solanum melongena wall. has strong linear correlation, which indicate that antioxidant capacity is mainly contributed by polyphenolic compounds. Although other vegetables show that some has liner correlation between $\mathrm{H}-\mathrm{ORAC} \mathrm{FL}_{\mathrm{FL}}$ and TPC, but not in all (Figs. 1 and 2). The range of $\mathrm{H}-\mathrm{ORAC} \mathrm{FL}_{\mathrm{FL}}$ values of the fruits show large variation (0.45-178 $\left.\mu \mathrm{mol} \mathrm{TEg}{ }^{-1}\right)$ as compared to vegetables and Limonia acidissima (Wood apple), Embilica officinalis (amla) and Psidium guajava (guava) have relatively high $\mathrm{H}-\mathrm{ORAC} \mathrm{FL}_{\mathrm{F}}$. The low level of antioxidant ability of Citrullus vulgaris (Melon) showed 


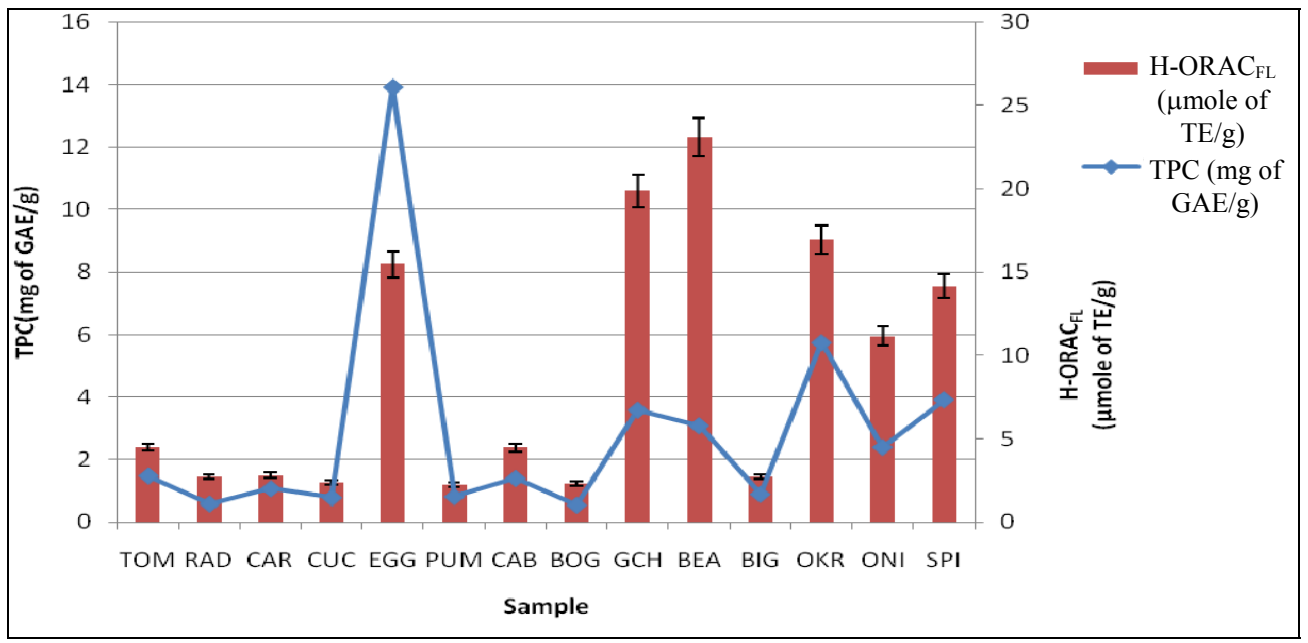

Fig. 1 Correlation between $\mathrm{H}-\mathrm{ORAC} \mathrm{FL}_{\mathrm{F}}$ values and TP (total phenolic) of vegetables and fruit samples.

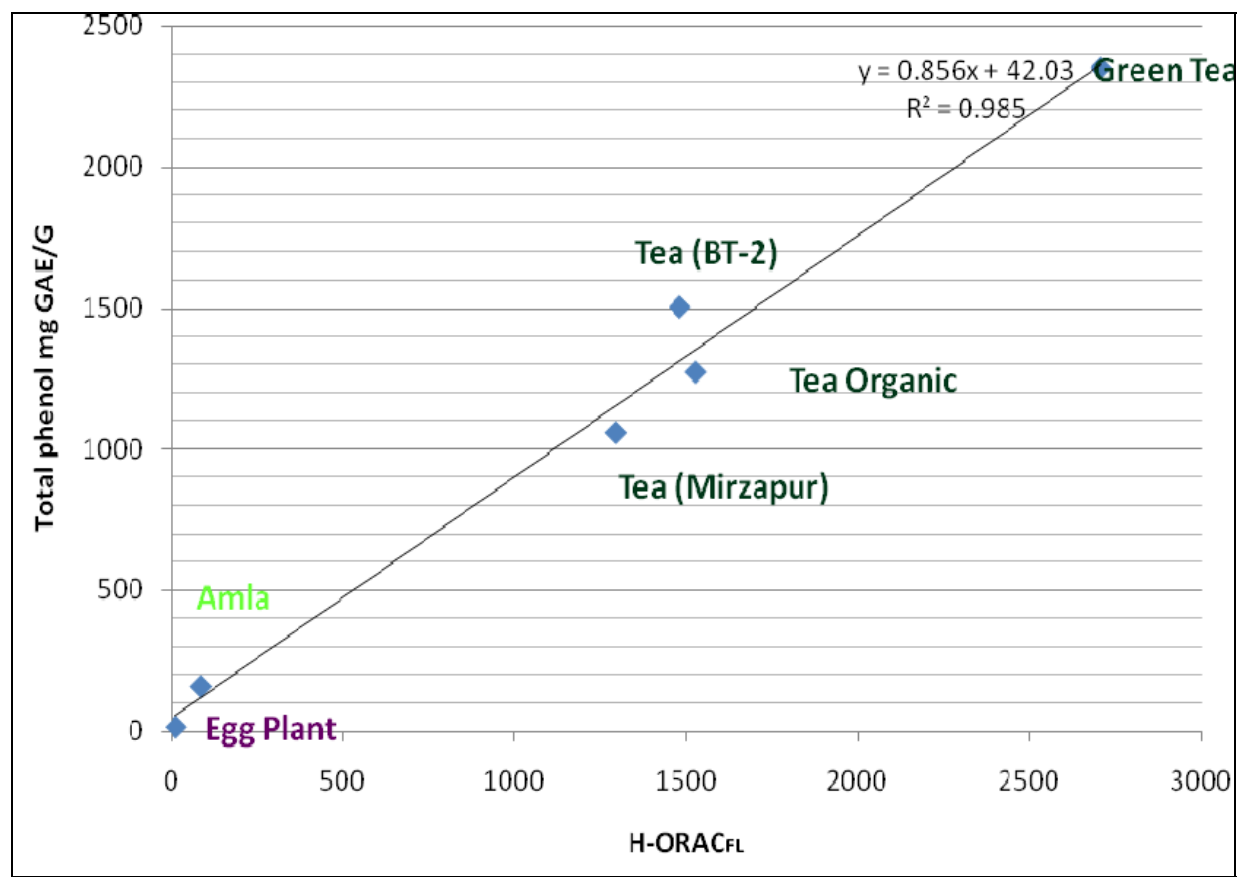

Fig. 2 Strong linera correlation between $\mathrm{H}-\mathrm{ORAC} \mathrm{FL}_{\mathrm{F}}$ content and total phenols of some selective food samples.

strong agreement with previously reported data [22, 23].

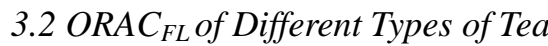

Table 2 represents the $\mathrm{H}-\mathrm{ORAC} \mathrm{FL}_{\mathrm{FL}}, \mathrm{L}-\mathrm{ORAC} \mathrm{FL}_{\mathrm{FL}}$, Total ORAC $\mathrm{FL}_{\mathrm{FL}}$ and TPC of four different types of tea samples. All four types of tea show high $\mathrm{H}-\mathrm{ORAC} \mathrm{FL}_{\mathrm{FL}}$ values $\left(1,242.07-2819.81 \mu \mathrm{mol}\right.$ of $\left.\mathrm{TEg}^{-1}\right)$ and green tea $(2,819.81 \pm 276.42)$ has highest antioxidant capacity compared to other type of tea samples produced by fermentation as previously reported. In agreement, all tea samples contain high amount of TPC and exhibit highly linear correlation with H-ORAC $C_{\mathrm{FL}}\left(\mathrm{R}^{2}=0.9855\right)$ (Fig. 2), indicate the strong agreement with previous studies that polyphenolic compounds present in tea samples are mainly contributed to their oxygen radical absorbance capacity.

\subsection{ORAC FL of Spice and Oil Seeds}

Six different spices and herb, five oilseeds were 
analyzed, which are commonly used in Bangladesh and their $\mathrm{H}-\mathrm{ORAC} \mathrm{C}_{\mathrm{FL}}, \mathrm{L}-\mathrm{ORAC} \mathrm{FL}_{\mathrm{FL}}$ are given in Table 3 with TPC. H-ORAC $\mathrm{FL}_{\mathrm{FL}}$ value of analyzed spices ranges from 70.41 to $272.82 \mu \mathrm{mol} \mathrm{TEg}^{-1}$. Comparison between $\mathrm{H}-\mathrm{ORAC} \mathrm{C}_{\mathrm{FL}}$ and L-ORAC $\mathrm{FL}_{\mathrm{FL}}$ of spices showed that Curcuma domestica, Carum roxburghianum Benth and Nigella sativa have more L-ORAC $\mathrm{FL}_{\mathrm{F}}$ value (29.75-1,575.24) as compared to H-ORAC $\mathrm{FL}_{\mathrm{FL}}$. In case of spices, the $\mathrm{H}-\mathrm{ORAC} \mathrm{C}_{\mathrm{FL}}$ and $\mathrm{L}-\mathrm{ORAC} \mathrm{C}_{\mathrm{FL}}$ values show strong agreement with previous studies and review [24]. Comparatively, spices having high value of $\mathrm{L}-O R A C_{\mathrm{FL}}$ and Curcuma domestica (Turmeric) shows both higher L-ORAC $\mathrm{FL}_{\mathrm{FL}}$ as well as, $\mathrm{H}-\mathrm{ORAC} \mathrm{FL}_{\mathrm{FL}}$. Which are contributing by ascorbic acid, caffeic acid, curcumin, eugenol essential oil, $p$-coumeric acid [21]. According to the values of total $\mathrm{ORAC}_{\mathrm{FL}}$ determined for individual spices in the descending order are:

Curcuma domestica $>$ Nigella sativa $>$ Carum roxburghianum Benth $>$ Foeniculam vulgare $>$ Capsicum annum $>$ Coriendrum sativum

The $\mathrm{H}-\mathrm{ORAC} \mathrm{FL}_{\mathrm{FL}}$ value of the oil seeds ranges from 53.75 to $133.86 \mu \mathrm{mol}$ of $\mathrm{TEg}^{-1}$ of $\mathrm{FW}$, whereas, comparatively less variation is observing in L-ORAC $\mathrm{FL}_{\mathrm{FL}}$ value ranges from 7.52 to 29.05 .

\subsection{ORAC $F$ of Legumes and Cereal}

The range of $\mathrm{H}-\mathrm{ORAC} \mathrm{FL}_{\mathrm{FL}}$ in five different types of legumes varies from 14.81 to 171.12 , whereas, L-ORAC $\mathrm{FL}_{\mathrm{FL}}$ ranges from 4.43 to $25.78 \mu \mathrm{mol} \mathrm{TEg}^{-1}$, later value is not so wide as compared to $\mathrm{H}-\mathrm{ORAC} \mathrm{CL}_{\mathrm{FL}}$. More precisely, Phaseolus mung Roxb.Lens esculenta Moench. (Black gram) showed highest $\mathrm{H}-\mathrm{ORAC} \mathrm{FL}_{\mathrm{FL}}$ and T-ORAC $\mathrm{FL}_{\mathrm{FL}}$ value whereas, Cicer arietum (Bengal gram -split) shows comparatively highest L-ORAC $\mathrm{FL}_{\mathrm{FL}}$ value (Table 4). According to the order of the anti-oxidant capacities of the different legumes are as follows:

Phaseolus mung Roxb. Lens esculenta Moench. > Phaseolus aureus Roxb $>$ Cicer arietum $>$ Lathyrus sativus $>$ Lenns esculentia

Only one cereal, popularly known as cheena (porso millet) is included in present study and shows more L-ORAC $_{\mathrm{FL}}\left(19.40 \mu \mathrm{mol} \mathrm{TEg}{ }^{-1}\right)$ value than hydrophilic fraction $\left(0.80 \mu \mathrm{mol} \mathrm{TEg}^{-1}\right)$, which is 24 times higher.

Table 2 Hydrophilic (H-ORAC ${ }_{F L}$ ), lipophilic $\left(L-O R A C_{F L}\right)$, total ORAC FL $_{\text {I }}$ and TPC of different types of tea.

\begin{tabular}{lllllll}
\hline Types of tea & Scientific name & Moisture $(\%)$ & $\begin{array}{l}\mathrm{H}-\mathrm{ORAC}_{\mathrm{FL}} \\
(\mu \mathrm{mol} \mathrm{TEg})\end{array}$ & $\begin{array}{l}\mathrm{L}-\mathrm{ORAC}_{\mathrm{FL}} \\
\left(\mu \mathrm{mol} \mathrm{TEg}^{-1}\right)\end{array}$ & $\begin{array}{l}\text { Total ORAC } \\
\left(\mu \mathrm{mol} \mathrm{TEg}^{-1}\right)\end{array}$ & $\begin{array}{l}\mathrm{TP}\left(\mathrm{mg}^{-1}\right. \\
\left.\mathrm{GAEg}^{-1}\right)\end{array}$ \\
\hline GreenTea & Camellia sinensis & N.D* & $2,819.81 \pm 276.42$ & $14.70 \pm 2.00$ & $2,834.51$ & $2,348.60$ \\
Tea organic & Camellia sinensis & 6.59 & $1,528.54 \pm 49.51$ & $12.66 \pm 2.80$ & $1,578.05$ & $1,271.10$ \\
Tea (BT-2) & Camellia sinensis & 5.84 & $1,573.73 \pm 162.48$ & $9.62 \pm 0.90$ & $1,583.33$ & $1,501.70$ \\
Tea (Mirzapur) & Camellia sinensis & 5.31 & $1,242.07 \pm 105.92$ & $20.74 \pm 3.47$ & $1,262.81$ & $1,056.74$ \\
\hline
\end{tabular}

*Not Done.

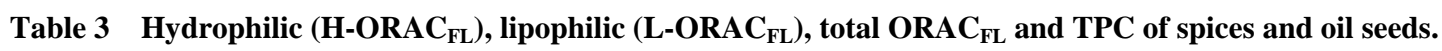

\begin{tabular}{|c|c|c|c|c|c|c|}
\hline Spices/Oil seeds & Scientific name & $\begin{array}{l}\text { Moisture } \\
(\%)\end{array}$ & $\begin{array}{l}\text { H-ORAC }{ }_{\mathrm{FL}} \\
\left(\mu \mathrm{mol} \mathrm{TEg}^{-1}\right)\end{array}$ & 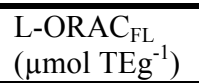 & 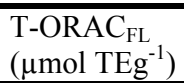 & $\begin{array}{l}\text { TP }\left(\mathrm{mg}^{-1}\right. \\
\left.\mathrm{GAEg}^{-1}\right)\end{array}$ \\
\hline RAD (Radhuni) & Carum roxburghianum Benth & N.D & $97.15 \pm 7.0$ & $462.94 \pm 77$ & 560.09 & 18.11 \\
\hline REC (Red chili) & Capsicum annum & 10.0 & $119.38 \pm 11.50$ & $68.02 \pm 0.0$ & 187.40 & n.d \\
\hline COR (Coriender) & Coriendrum sativum & 11.2 & $61.68 \pm 1.7$ & $29.75 \pm 0.0$ & 91.43 & n.d \\
\hline TUR (Turmeric) & Curcuma domestica & 13.1 & $272.82 \pm 1.0$ & $1,575.24 \pm 40$ & $1,848.06$ & n.d \\
\hline MUO (Mouri) & Foeniculam vulgare & N.D & $209.17 \pm 23.97$ & $88.58 \pm 5.5$ & 297.75 & 32.16 \\
\hline KAL (Kalozeera) & Nigella sativa & N.D & $146.77 \pm 14.40$ & $456.35 \pm 13.8$ & 603.12 & n.d \\
\hline LIN (Linseed) & Linum usitatissimum & 6.5 & $60.51 \pm 5.1$ & $18.60 \pm 1.3$ & 79.11 & 16.55 \\
\hline MUB(Mustardbrown) & Basica nigra & 8.5 & $133.86 \pm 7.8$ & $29.05 \pm 1.2$ & 162.91 & 28.80 \\
\hline MUY (Mustard yellow) & Basica nigra & 8.5 & $130.41 \pm 8.9$ & $7.52 \pm 1.28$ & 137.93 & 26.94 \\
\hline SBL (Sesame black) & Sesamum indicum & 5.3 & $61.97 \pm 8.0$ & $9.31 \pm 1.10$ & 71.28 & 17.71 \\
\hline SBR (Sesame brown) & Sesamum indicum & 5.3 & $53.75 \pm 9.9$ & $19.93 \pm 2.87$ & 73.68 & 15.92 \\
\hline
\end{tabular}

N.D: Not Done, n.d: not detected. 

Indigenous Foods of Asian Tropical Regions

Table 4 Hydrophilic (H-ORAC ${ }_{F L}$ ), lipophilic (L-ORAC ${ }_{F L}$ ), total ORAC and TPC of legumes and cereal.

\begin{tabular}{lllllc}
\hline Legumes/cereal & Scientific name & $\begin{array}{l}\mathrm{H}-\mathrm{ORAC}_{\mathrm{FL}} \\
(\mu \mathrm{mol} \mathrm{TEg})\end{array}$ & $\begin{array}{l}\mathrm{L}-\mathrm{ORAC}_{\mathrm{FL}} \\
\left(\mu \mathrm{mol} \mathrm{TEg}^{-1}\right)\end{array}$ & $\begin{array}{l}\mathrm{T}-\mathrm{ORAC} \\
\left(\mu \mathrm{mol} \mathrm{TEg}^{-1}\right)\end{array}$ & $\begin{array}{l}\mathrm{TP}(\mathrm{mg} \\
\left.\mathrm{GAEg}^{-1}\right)\end{array}$ \\
\hline BLG (Black gram) & Phaseolus mung Roxb.Lens esculenta Moench. & $171.12 \pm 25.91$ & $5.40 \pm 0.65$ & 176.52 & 13.68 \\
GRG (Green gram) & Phaseolus aureus Roxb & $32.65 \pm 6.41$ & $20.45 \pm 2.29$ & 53.10 & 8.58 \\
KHE (Kheshari dal) & Lathyrus sativus & $17.85 \pm 1.03$ & $4.43 \pm 1.51$ & 22.28 & 7.52 \\
LEN (Lentil) & Lenns esculentia & $14.81 \pm 1.48$ & $4.77 \pm 1.20$ & 19.58 & 5.93 \\
BEG (Bengal gram) & Cicer arietum & $18.00 \pm 3.03$ & $25.78 \pm 2.61$ & 33.78 & 7.45 \\
CHE (Cheena) & Panicum milliaceum & $0.80 \pm 1.13$ & $19.40 \pm 2.29$ & 20.20 & 4.76 \\
\hline
\end{tabular}

Increasing interest in the effects of food habits and degenerative diseases has stimulated the present study to evalute the commonly consumed indigenous foods of Bangladesh for their anti-oxidant capacity, as well as their contributory phenolic compounds. As a first attempt to screen the Bangladeshi foods, forty one food samples were selected, including vegetables, fruits, tea, spices, oil seeds, legumes and cereal. Of all the vegetables, Solanum melongena wall. (egg plant) contains highest TPC, although Phaseolus coccineus (bean) show the highest $\mathrm{H}-\mathrm{ORAC} \mathrm{FL}_{\mathrm{FL}}$ value, most probably contributed by flavanols, flavonols (quercetin, kaemdferol) isoflavones [25].

In most of the vegetables, total ORAC $\mathrm{FL}_{\mathrm{FL}}$ values are contributing by their $\mathrm{H}-\mathrm{ORAC} \mathrm{FL}_{\mathrm{FL}}$ content, except Capsicum annum, Solanum melongena wall. Phaseolus coccine. Three of these vegetables have considerable amount of $\mathrm{L}_{-} \mathrm{ORAC}_{\mathrm{FL}}$ as compared to other vegetables. As a result, Capsicum annum exhibit the highest $\mathrm{T}-\mathrm{ORAC} \mathrm{CL}_{\mathrm{FL}}$ value. Among the vegetables analyzed, $\mathrm{ORAC}_{\mathrm{FL}}$ values of 10 vegetables are present in USDA database [23] and comparison revealed that some the findings of present study are comparable to USDA database but different level of variation also found in some cases, especially in TPC. Already, several research findings established that high $\mathrm{H}-\mathrm{ORAC} \mathrm{FL}_{\mathrm{FL}}$ value of fruit samples correlate with the diversified phenolics compounds distributed in fruits [25]. In present study, among the six fruit samples three has linear correlation between $\mathrm{H}_{-} \mathrm{ORAC} \mathrm{C}_{\mathrm{FL}}$ \& TPC except Psidium guajava, Embilica officinalis and Aegle marmelos. Additionally, a review article reported that environmental factors have a major effect on polyphenolic content, includes soil type, sun exposure, rainfall, greenhouse or field, biological culture, hydroponic culture, fruits yield from tree etc. Exposure to light has a considerable effect on most flavonoids and degree of ripeness considerable effects on the concentrations and proportion [26].

All teas are derived from the leaves of Camellia sinensis, but difference in $\mathrm{ORAC}_{\mathrm{FL}}$ value might be explain by the variation in catechin content due to fermentation processing. During the fermentation process polyphenol oxidase enzyme of the leaves comes to the contact of catechins and leads to the conversion of catechins to their dimmer and polymers known as theaflavins and thearubigins, which has no ORAC value [27]. The antioxidant properties of polyphenols are reported for their health beneficial roles which include anticancer [28], antiviral, antimicrobial [29] and anti-inflammatory [30]. Review article on health beneficial role of tea reported that Epigallocatechin gallate (EGCG), also known as Epigallocatechin 3-gallate, ester of epigallocatechin and gallic acid, the most abundant catechin in tea and responsible for antioxidant capacity [27]. Flax seed or linseed contains at least three different types of phenolics: phenolic acids, flavonoids and lignans and quantification showed that 8 to $10 \mathrm{~g}$ of total phenolics $\mathrm{kg}^{-1}$ of flax, 35-70 mg flavonoids $100 \mathrm{~g}^{-1}[30,31]$ and secoisolariciresinol diglucoside (SDG) ranges from 1 to $26 \mathrm{mg} \mathrm{g}^{-1}$ [32]. Another contributory nutrient is vitamin E, comprises by alpha-tocopherol (7 mg 100 $\left.\mathrm{g}^{-1}\right)$, delta-tocopherol (10 $\left.\mathrm{mg} \quad 100 \quad \mathrm{~g}^{-1}\right)$ and gamma-tecopherol (552 mg $100 \mathrm{~g}^{-1}$ ) [33]. Separation of SDG lignan from flaxseed has been difficult because SDG is a plant lignan (polyphenol) found in its highest concentration in flax seeds. The lignin of 
flax seeds adheres tightly to the seed, test results have shown in other report that SDG acts as more potent antioxidant than vitamin $\mathrm{E}$. The higher the concentration of SDG, the greater the antioxidant effect has. Antioxidant capacity mostly is contributed by lignan, omega-3-fatty acid (alpha-linolenic acid). Lignans like SDG in flaxseed are called phytoestrogens because they resemble the female hormone estrogen and they attach to the same receptors on the cells where estrogen would, thus reducing estrogen's effects by displacing it from the cells. Linseed variety of present study showed 16.55 $\mathrm{g}$ of $\mathrm{TPKg}^{-1}$ seeds whereas, the ORAC $\mathrm{FL}$ value is corresponds with the content of Vitamin E reported in reference. Most of the bioactive compounds present in different legumes are lentil (flavans), mung beans (genistein), peas (flavonols, beta-sisterol, campesterol, stigmasterol) are contributory to the H-ORAC ${ }_{\mathrm{FL}}$ [21].

Only one cereal, popularly known as cheena (porso millet) is included in present study and shows 24 times higher value of L-ORAC $\mathrm{FL}_{\mathrm{FL}}\left(19.40 \mu \mathrm{mol} \mathrm{TEg}^{-1}\right)$ than hydrophilic fraction $\left(0.80 \mu \mathrm{mol} \mathrm{TEg}^{-1}\right)$. The obtained result has strong indications that polyphenols (tocopherol, flavonoids and phenolic acids) may be the major contributing compounds for antioxidant activity. This activity is believed to be mainly due to their redox properties [6], which play an important role in adsorbing and neutralizing free radicals, quenching singlet and triplet oxygen, or decomposing peroxides. The present study findings strongly suggest that phenolic compounds are important components of the food samples assayed, and some of their health beneficial effects could be attributed by the presence of these valuable constituents. In present study, 41 selected indigenous and commonly consumed food samples of Bangladesh evaluated for their antioxidant capacity and revealed some unique and interesting indications for functionality of foods and also identified several potent food source of antioxidants in local diet.

\section{Conclusions}

Present study findings initiate a new dimension in the field of food science research in Bangladesh. As review article on food composition databases for bioactive food components explained the necessity to build a detailed food functional database. Therefore, present study would be the significant addition to the data generation to create a data base of antioxidant activity and total phenolic contents of Bangladeshi indigenous commonly consumed foods, although, further study is required to elucidate the health beneficial role (in vitro and vivo) and detailed identification and quantification of the bioactive components.

\section{Acknowledgment}

The financial support from the M/S KIRIN holdings Ltd, Japan as a "UNU-Kirin fellowship" is gratefully acknowledged.

\section{References}

[1] M.G.L. Hertog, E.J. Feskens, P.C. Hollman, M.B. Katan, D. Kromhout, Dietary antioxidant flavonoids and risk of coronary heart disease: The zupten elderly study, Lancet 342 (1993) 1007-1011.

[2] I. Jialal, S.M. Grundy, Effect of supplementation with alpha tocopherol, ascorbate and beta-carotene on low-density lipoprotein oxidation, Circulation 88 (1993) 2780-2786.

[3] B.N. Ames, M.K Shigenaga, T.M. Hagen, Oxidant, antioxidant, and the degenerative diseases of aging, Proc. Natl. Acad. Sci. USA 90 (1993) 7915-7922.

[4] J.M.C. Gutterridge, B. Halliwell, Free radicals and antioxidants in aging and disease: Fact or fantasy, in: Antioxidants in Nutrition, Health and Disease, Oxford University Press, UK, 1994, pp. 111-135.

[5] K. Briviba, H. Sies, Non enzymatic antioxidant defence systems, in: B. Feri (Ed.), Natural Antioxidant in Human Health and Disease, Academic Press, New York, 1994, pp. 107-128.

[6] C.A. Rice-Evans, N.J. Miller, G. Paganga, Antioxidant properties of phenolic compounds, Trends in Plant Sciences 2 (4) (1997) 152-159.

[7] J.H. Weisburger, Mechanisms of action of antioxidants as exemplified in vegetables tomatoes and tea, Food and Chemical Toxicology 39 (9/10) (1999) 943-948.

[8] R.A. Larson, The antioxidants of higher plants, Phytochemistry 27 (1998) 969-978. 


\section{Antioxidant Capacity and Total Phenol Content of Commonly Consumed Indigenous Foods of Asian Tropical Regions}

[9] C.A. Hall, S.L. Cuppet, Structure-activities of natural antioxidants, in: O.I. Aruoma, S.L. Cuppet (Eds.), Antioxidant Methodology in vivo and in vitro Concepts, University of Illinois Press, Champaign, IL, 1997, pp. 1007-1011.

[10] S. Arai, Y. Morinaga, T. Yoshikawa, E. Ichiishi, Y. Kiso, M. Yamazaki, et al., Recent trends in functional food science and the industry in Japan, Biosci. Biotechnol. Biochem. 66 (10) (2002) 2017-2029.

[11] B.N. Ames, L.S. Gold, W.C. Willet, The causes and prevention of cancer, Proc. Natl. Acad. Sci. USA 92 (1995) 5258-5265.

[12] M.N. Diaz, B. Frei, J.F. Keaney, Antioxidants and atherosclerotic heart disease, New Engl. J. Med. 337 (1997) 408-416.

[13] T. Yamamoto, M. Yoshimura, F. Yamaguchi, T. Kouchi, R. Tsuji, M. Saito, et al., Anti-allergic activity of naringenin chalcone from a tomato skin extract, Biosci. Biotechnol. Biochem. 68 (8) (2004) 1706-1711.

[14] B.A. Graf, P.E. Milbury, J.B. Blumberg, Flavonols, flavones, flavonones and human health: Epidemiologic evidence, J. Med. Food 8 (3) (2005) 281-290.

[15] S. Hossain, N. Shaheen, M. Mohiduzzaman, C.P. Banu, Antioxidant capacity and total phenol content of the commonly consumed selected vegetables of Bangladesh, Malaysian J. Nutr. 17 (3) (2011). (in press)

[16] X. Wu, G.R. Beecher, J.M. Holden, D.B. Haytowitz, S.E. Gebhardt, R.L. Prior, Lipophilic and hydrophilic antioxidant capacities of common foods in the United States, J. Agric. Food Chem. 52 (2004) 4026-4037.

[17] D. Huang, B. Ou, M. Hampsch-Woodill, J.A. Flanagan, E.K. Deemer, Development and validation of oxygen radical absorbance capacity assay for lipophilic antioxidants using randomly methylated $\beta$-Cyclodextrin as the solubility enhancer, J. Agric. Food Chem. 50 (2002) 1815-1821.

[18] D. Huang, B. Ou, M. Hampsch-Woodill, J.A. Flanagan, R.L Prior, High-throughput assay of oxygen radical absorbance capacity (ORAC) using a multichannel liquid handling system coupled with a microplate Fluorescence reader in 96-well format, J. Agric. Food Chem. 50 (2002) 4437-4444.

[19] V.L. Singlleton, J.A. Rossi, Colorimetry of total phenolics with phosphomolybdic-phosphotungstic acid reagents, Am. J. Enol. Vitic. 16 (1965) 144-158.
[20] B. Ou, M. Hampsch-Woodill, R.L. Prior, Development and validation of an improved oxygen radical absorbance capacity assay using fluorescein as the fluorescent probe, J. Agric. Food Chem. 49 (2001) 4619-4926.

[21] J.A.T. Pennington, Study review: Food composition databases for bioactive food components, J. Food Comp. and Anal. 15 (2002) 419-434.

[22] X. Wu, J.M. Holden, D.B. Haytowitz, S.E. Gebhardt, G. Beecher, R.L. Prior, Development of a database for total antioxidant capacity in foods: A preliminary study, J. Food Comp. and Anal. 17 (2004) 407-422.

[23] J.J. Macheix, A. Fleuriet, J. Billot, Fruit Phenolics, CRC Press, Inc. Boca Raton, Florida, 1990.

[24] M. Suhaj, Spice antioxidants isolation and theirantiradical activity: A review, J. Food Comp. and Anal. 19 (2006) 531-537.

[25] C. Manach, A. Scalbert, C. Morand, C. Re'me'sy, L. Jime nez, Polyphenols: Food sources and bioavailability, Am. J. Clin. Nutr. 79 (2004) 727-747.

[26] S. Sang, C.S. Yang, C.T. Ho, Peroxidase-mediated oxidation of catechins, Phytochemistry Reviews 3 (2004) 229-241.

[27] T.H. Tsai, T.H. Tai, Y.C. Chein, C.W. Lee, P.J. Tsai, In vitro activities against cariogenic streptococci and their antioxidant capacities: A comparative study of green tea versus different herbs, Food Chem. 110 (2008) 859-864.

[28] A. Devine, J.M. Hodgson, I.M. Dick, R.L. Prince, Tea drinking is associated with benefits on bone density in older women, Am. J. Clin. Nutr. 86 (2007) 1243-1247.

[29] L. Diane, F.A.C.N. McKay, B. Jeffrey, F.A.C.N. Blumberg, Roles for epigallocatechin gallate in cardiovascular disease and obesity: An introduction, J. Am. College of Nutr. 26 (4) (2007) 362S-365S.

[30] B.D. Oomah, E.O. Kenaschuk, G. Mazza, Phenolic acids in flaxseed, J. Agric. Food Chem. 43 (1995) 2016-2019.

[31] B.D. Oomah, G. Mazza, Flax seed products for disease prevention, in: G. Mazza (Ed.), Functional Foods: Biochemical \& Processing Aspects, Technomic Publishing, Lancaster, PA, 1998, pp. 91-138.

[32] A.D. Muir, Flax lignans-analytical methods and how they influence our understanding of biological activity, J. AOAC Int. 89 (2006) 1147-1157.

[33] J.K. Daun, R. Przybylski, Environmental effects on the composition of four Canadian flax cultivars, Proc. Flax Inst. 58 (2000) 80-91. 